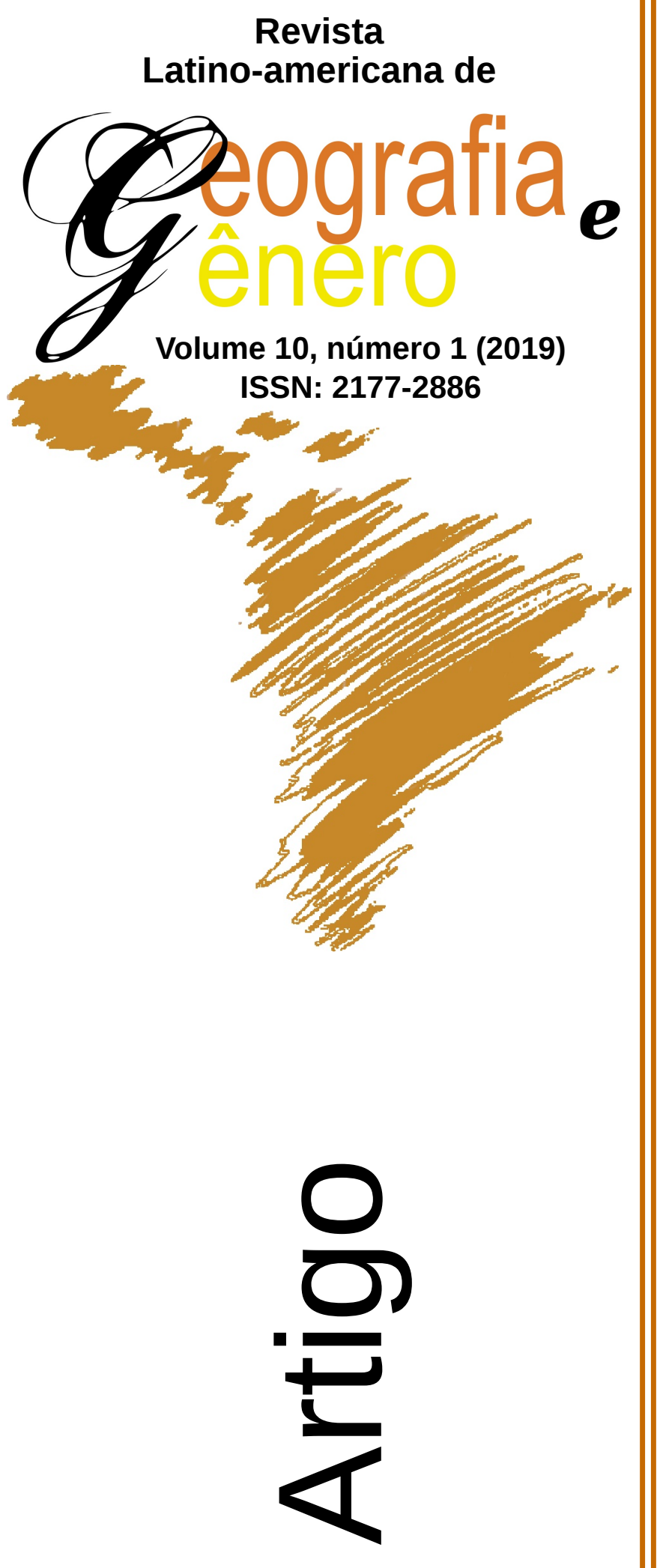

\title{
Las Personas Trans Feminizadas y la Prostitución como Último Recurso para la Supervivencia
}

As Pessoas Transexuais Feminizadas e a Prostituição como um Último Recurso para a Sobrevivência

Trans-Feminized Persons and Prostitution as a Last Resort for Survival

\section{Irma Elizabeth Chazarreta}

Universidad Nacional de Santiago del Estero Argentina irma939@hotmail.com

Como citar este artigo:

CHAZARRETA, Irma Elizabeth. Las Personas Trans Feminizadas y la Prostitución como Último Recurso para la Supervivencia. Revista Latino Americana de Geografia e Gênero, v. 10, n. 1, p. 233-255, 2019. ISSN 2177-2886.

Disponível em:

http://www.revistas2.uepg.br/index.php/rlagg 


\title{
Las Personas Trans Feminizadas y la Prostitución como Último Recurso para la Supervivencia
}

\author{
As Pessoas Transexuais Feminizadas e a Prostituição como um Último \\ Recurso para a Sobrevivência
}

\section{Trans-Feminized Persons and Prostitution as a Last Resort for Survival}

\section{Resumen}

El presente trabajo busca analizar las concepciones que tienen las propias personas trans feminizadas ${ }^{1}$ sobre la prostitución, y describir las situaciones por las que transitan en ese contexto. Se trabajó con entrevistas en profundidad desde un enfoque etnográfico. Caber señalar que este trabajo es parte de un proceso más amplio que se encuentra en el marco de la tesis de maestría. Las personas trans feminizadas ingresan a la actividad como último recurso para obtener dinero frente a las discriminación y exclusión del ámbito familiar y educativo y la imposibilidad de ser empleada en otra actividad por su identidad. En la calle, donde ofrecen sus servicios, representan su identidad como la desean, pero transitan situaciones de violencia en todas sus expresiones. En el único lugar que encuentra apoyo y contención es en las organizaciones de la sociedad civil.

Palabras-Clave: Personas Trans Feminizadas; Exclusión; Prostitución; Violencias.

\section{Resumo}

O presente trabalho busca analisar as concepções que pessoas transgêneras têm sobre prostituição e descrever as situações pelas quais elas transitam nesse contexto. Trabalhamos com entrevistas aprofundadas de uma perspectiva etnográfica. Deve-se notar que este trabalho é parte de um processo mais amplo que faz parte da tese de mestrado. As pessoas trans feminizadas entram na atividade como último recurso para obter dinheiro em face da discriminação e exclusão do ambiente familiar e educacional e da impossibilidade de ser empregado em outra atividade por causa de sua identidade. Na rua, onde oferecem seus serviços, eles representam sua identidade como desejam, mas as situações de violência em todas as suas expressões passam. No único lugar que encontra apoio e contenção está nas organizações da sociedade civil.

Palavras-Chave: Pessoas Trans Feminizadas; Exclusão; Prostituição; Violência.

\section{Abstract}

This paper seeks to analyze the conceptions that the trans feminized people themselves have about prostitution, as well as to describe the situations they go through in such context. For this purpose, we worked with in-depth interviews from an ethnographic approach in an attempt to know the most real context where these events happen. It should be noted that this work is part of a broader process that is within the framework of a master's thesis. Transfeminized persons enter the activity as a last resort to obtain money due to the discrimination they face as well as the exclusion from the family and educational environment and the impossibility of being employed in another activity because of their identity. In the street, where they offer their services, they represent their identity as they wish, but they also experience all types of violence. The only place they can find support is in civil society organizations.

Keywords: Trans-Feminized Persons; Exclusion; Prostitution; Violence. 


\section{Introducción}

La prostitución no es un fenómeno nuevo, sin embargo, el desarrollo de la globalización ha potenciado cifras inimaginables en época anteriores. Actualmente, transciende las fronteras locales y nacionales. Se manifiesta de manera compleja en la comunidad internacional, donde el factor económico, de género y de clase, son parte, así como las familias, las sociedades, el Estado y la globalización.

Dentro del feminismo se haya la discusión sobre la prostitución con argumentos sólidos cada una de sus posturas, que aún no han llegado al consenso. Por un lado, se la considera una violencia contra las mujeres que debe ser erradicada, se la define como un espacio desigual, donde el varón ejerce dominio sobre la mujer ocupando ella el lugar de subordinada. En este sentido, es definida como el comercio del cuerpo de la mujer otorgado a los varones a cambio de dinero. Es decir, siempre que se conceptualiza a la prostitución en la ideología patriarcal se la define a partir de la relación mercantil del cuerpo (LAGARDE y de LOS RÍOS, 2011). La autora describe a la prostitución como un espacio social, cultural y político de la sexualidad prohibida, explícita y centralmente erótica. Por otro lado, buscan la regulación de la prostitución porque entienden que es la mejor vía para garantizar la protección de quienes la ejercen. Consideran a la prostitución un trabajo, con posibilidad de sindicalizarse y reclamar por los derechos laborales y sociales, entre ellos: obra social, jubilación y vivienda. No desconocen las desigualdades de género mediante la prostitución, pero ven en el empoderamiento y en la agremiación de las trabajadoras sexuales herramientas para mejorar su calidad de vida y así enfrentar situaciones de violencia tanto de la policía como de los/as proxenetas y los prostituyentes.

En este debate podemos encontrar diferente modelos de regulación jurídica en materia de prostitución ${ }^{2}$ que en esta oportunidad no profundizare porque el eje central de este artículo son las voces de las protagonistas. Se busca analizar las concepciones que tienen las propias personas trans feminizadas sobre la

1 Investigadora asociada del Instituto de Estudios para el Desarrollo Social de la Facultad de Humanidades, Ciencias Sociales y Salud de la Universidad Nacional de Santiago del Estero. Integrante del Grupo de Investigación Género, Políticas y Derechos. Profesora y Licenciada en Educación para la Salud. Magister en Salud Sexual y Reproductiva de la Universidad Nacional de Córdoba. Tesista del Doctorado en Humanidades de la Universidad Nacional de Tucumán. Ex becaria del Consejo Nacional de Investigaciones Científicas y Técnicas CONICET. Correo electrónico: irma939@hotmail.com

En torno a las identidades de género hay un debate político en el interior de las organizaciones civiles, en este trabajo no se hará referencia a ello. Las autodenominaciones que utilizan dentro del colectivo son variables y heterogéneas, algunas se consideran travestis, trans a secas, mujeres trans, personas trans, o "personas trans feminizadas". Decido trabajar con esta última denominación porque es la más inclusiva y así se identifica la mayoría que forma parte del estudio. Se entiende por trans, a la persona cuya identidad de género implica un cuestionamiento del esquema binario varón-mujer, e incluye diversas identidades. En este trabajo no se utiliza "mujeres trans" porque al momento de entrevistar no todas se sienten identificada con esa categoría, se encuentran en proceso de construcción de la identidad donde en algunos casos no tienen identificado claramente a que género pertenecer o simplemente no quieren encasillarse en categorías, sino viven su identidad como la sienten, aunque su apariencia física, y el nombre adoptado sea femenino.

2 Para más información consultar Rubio, 2008; Berkins, Lohana y Korol, Claudia (2007). 
prostitución, y describir las situaciones por las que transitan en ese contexto. Para ello he trabajado con enfoque etnográfico, en el que se intenta conocer la perspectiva de las actoras en el contexto más real donde suceden los hechos. Se ha utilizado herramientas metodológicas como entrevistas en profundidad realizadas a 10 personas trans feminizadas y situaciones conversacionales en diversos contextos ya que compartimos muchas actividades educativas, sociales, comunitarias y organizacionales desde hace más de 6 años. La mayoría de las entrevistadas se encuentran en un rango etario que va de los 28 a los 60 años de edad, solo una de ellas tiene 18 años al momento de entrevistar. La mayoría actualmente ejerce la prostitución en las calles de Santiago del Estero. Todas pertenecen a familias de bajos recursos, en la mayoría de los casos la prostitución constituye una alternativa para obtener dinero. Estas tareas desarrolladas se basan en lo que Quirós plantea:

el antropólogo (co) produce conocimiento no sólo con el intelecto y la palabra, sino también con el cuerpo, el olfato, la sensación, la intuición, la comunicación no verbal, el juicio, el afecto. También significa que eso que solemos llamar "perspectiva/s nativa/s" o "perspectiva/s del/los actor/es" debería ser entendido menos como un punto de vista "intelectual" - una forma de pensar o representar el mundo- y más como un punto de vista "experiencial", es decir, cierta/s forma/s y posibilidad/es de estar, producir y crear vida social (formas que nosotros, antropólogos, construimos a partir de nuestra/s propia/s experiencia/s etnográfica/s). (QUIRÓS, 2014, p. 9).

Dentro del trabajo etnográfico, se toma la observación participante como una forma de interacción que se tiene con las informantes, donde según Guber (2004, p. 26) "la participación supone desempeñar ciertos roles locales (...) entre el hacer y conocer, participar y observar", manteniendo una distancia, pero al mismo tiempo involucrándose en las actividades que realizan. Según Bourgois las técnicas etnografías de observación participante, han demostrado ser las más adecuadas que la metodología cuantitativa para documentar la vida de los individuos por la sociedad hostil. Para ello establecer lazos de confianza es de suma importancia, proceso que requiere tiempo, pues es posible que surja preguntas incisivas con respecto a temas personales y esperar respuestas serias y reflexivas (BOURGOIS, 1995).

Sabemos que "la prostitución no es un fenómeno unívoco, mucho menos uniforme y su heterogeneidad se complejiza con las diversas formas que la prostitución asume no sólo en distintos contextos y mercados, sino también en términos históricos y culturales" (DAICH, 2012, p. 8). La prostitución es un tema complejo, por lo tanto requiere ser pensada en cada terreno local, donde se pueda analizar la situación de las personas otorgándoles oído a sus voces. Y se pueda revelar que la prostitución no es un fenómeno homogéneo y que la lógica de la dominación masculina puede tomar diferentes formas en distintos estratos sociales (DAICH, 2012). Entonces se puede decir que la prostitución ocurre en un vasto y diverso mercado del sexo en el que innumerables escenarios son posibles. 


\section{La Prostitución... es el Último Recurso que Nosotras Optamos}

La cultura marca a los seres humanos con el género y a su vez la percepción de todo lo demás: lo social, lo político, lo religioso, lo cotidiano; en el que existe una lógica de poder, de dominación (LAMAS, 1995). La percepción que se tienen de las personas es que deben ser varón o mujer, quienes rompen esta estructura como las personas trans feminizadas deben soportar diferente humillaciones y maltratos por su identidad de género. El incumplimiento a la norma, produce una crisis al interior de la familia, y trae aparejado situaciones de discriminación, siendo el proceso de transformación lo más traumático para la familia (CHAZARRETA, 2016). Reiterados malos tratos y exclusiones hace que se alejen de la misma y busquen refugio en amistades que generalmente lo encuentran con personas que atraviesan la misma situación. En este sentido, Rosa señala lo siguiente:

- Las únicas que te acompañan en ese momento son las chicas de la calle. Nadie más te acompaña, todos los demás te condenan, te dan vuelta la cara. Al contrario, pierdes a un montón de gente cuando empiezas la calle, pierdes a la poca gente que te mira más menos bien de tu familia, cuando se enteran que sales a trabajar a la calle directamente te dejan de hablar, la policía, toda la gente, recibes todo el rechazo de la sociedad. Digamos que las únicas que te apoyan en la calle son las chicas que están en las mismas condiciones que vos, tu compañera de parada.

- ¿y cómo llegas a ella?

- Llego a ella porque...mmm... Necesitaba a alguien con quien hablar sobre lo que yo era y en mi familia lo que yo era es...mal visto. Entonces yo me he ido acercando y conversando con ella, haciendo mi grupo de amigas y ellas me han ido aceptando a mí también... (Rosa, 2013).

Las situaciones de discriminación sufridas en la infancia y en la adolescencia conllevan muchas veces, la decisión de abandonar el hogar y la escuela, vivencias que quedan tatuadas en el cuerpo y condicionan las posibilidades en término de inclusión social y acceso a empleos, lo que produce la necesidad de sostenerse económicamente desde muy jóvenes. Coincido con Silva (2009) cuando señala que las travestis son un grupo 
vulnerable frente a las violencias, son el grupo que mayor violencia y preconceptos padecen porque marca la transgresión nítida y visual por lo tanto enfrentan el poder heteronormativo. "En este marco la prostitución aparece como una de las pocas alternativas en las que se puede combinar el ejercicio de la identidad travesti/transexual con un ingreso económico suficiente para vivir" (BERKINS y FERNÁNDEZ, 2013:111). Y además, las relaciones sociales y de amistad que establecen en ese espacio que en otros no lo consiguen. A diferencia de lo que señalan las autoras en el trabajo de campo, aparece el ingreso como insuficiente para vivir:

(...) nadie quiere ir a la calle, siempre termina siendo el último recurso. Lo que pasa que a dónde iba a buscar trabajo siempre me pedían que vista un género que no era el mío (Rosa, 2013).

Ejercer la prostitución...para mí es un último recurso que nosotras optamos por el solo hecho de que yo tengo una profesión y no la puedo conseguir por mi condición sexual o sea por mi imagen... (Madelyn, 2014).

He buscado trabajo... y el único lugar donde una chica trans era aceptada era en la calle...yo he preferido ir a la calle con tal de no dejar de ser yo misma, de ponerme la pollerita que yo quería, de pintarme, de dejarme el pelo largo, y ser la mujer que hoy soy... (Rosa, 2014).

Vivir de la prostitución solamente, no te alcanza para cubrir las necesidades, escaso para comer y algunas que otras cosas... a mí no me alcanza (cuaderno de campo).

Existen discursos sociales en los que la prostitución parece ser una elección de las personas trans feminizadas, sin embargo, poco o nada se dice de la exclusión del mercado laboral. En este contexto, resulta imposible plantear el tema en términos de decisiones libres y autónomas cuando es un espacio de supervivencia y de reconocimiento de su identidad.

En contextos de diálogo y debate sobre la prostitución, si es o no un trabajo Berkins y Korol señalan lo siguiente:

Es el Estado quien nos condena a sobrevivir de la prostitución. El único medio de supervivencia que tenemos, es la prostitución. Por lo tanto para nosotras, más allá de las condiciones, si son precarias o no, o en las condiciones en que se establezcan, no es un trabajo. Para nosotras va a ser un trabajo, cuando tengamos alternativas de elección. Cuando digamos, por ejemplo, "ya soy oficinista gano tanto, pero en la esquina gano mucho más...". Entonces sí consideraríamos que es un trabajo que se puede elegir $(2007$, p. 16).

En este sentido, existe una marcada diferencia entre la realidad que vivencian las mujeres que ejercen la prostitución por elección ante una 
variedad de ofertas laborales, y las personas trans feminizadas, que lo hacen por la discriminación que genera su identidad de género. Si bien la mayoría de las personas trans para referirse a la tarea que realizan lo señalan como "trabajo sexual" porque durante el período que lo ejercen, subsisten y se mantienen económicamente a través de él, pero no quiere decir que lo eligen como trabajo, o del que quieran vivir el resto de sus vida, sino al contrario, la mayoría quiere salir de ese ámbito. Por ende "el deseo de ser travesti no trae aparejado de suyo la elección del ejercicio de la prostitución" (BERKINS y FERNÁNDEZ, 2013, p. 112).

En la calle, las personas trans feminizadas representan su identidad como la desean, reconstruyen su autoestima, sus deseos pueden desplegarse con mayor libertad. Al mismo tiempo el entorno está condicionado por patrones culturales que moldean las conductas y comportamientos de las personas que ingresan al ámbito de la prostitución. Allí la construcción del género femenino no es a partir de ese ropero familiar en el que cuelgan prendas de madre y hermanas sino proviene ahora de escenas construidas sobre la base de un estereotipo de mujer definida, siendo la mujer vedette y la mujer prostituta las referentes (FERNÁNDEZ, 2007). Al respecto, Juana (2014) menciona lo siguiente:

Yo creo que a nosotras el trabajo sexual nos atraviesa absolutamente todo, inclusive nuestros deseos intimos, nos modifica hasta eso, te formatea de tal manera. Además fijate vos, la construcción trans que nosotras hacemos, la construcción femenina es que sean deseosas de sexo, porque no decimos: quiero ser como mi mamá. No. Tengo que ser perfecta con el cuerpo, perfecta con la cara... divina, no tenés que tener dolencias.

Podemos decir que para pertenecer al ámbito de la prostitución significa encajar en un formato que moldea los deseos íntimos, la identidad, la sexualidad trans, el cuerpo y la subjetividad. Es un entorno, donde lo femenino se somete a los deseos de los varones quienes según el imaginario colectivo tienen el poder económico y sexual. Desde esta mirada, lo femenino sufre doble opresión, no solo por la desigualdad según la clase, sino de raza y género cada una de ellas afecta a la otra (LAGARDE, 2011).

Aquello que en su momento constituye la única alternativa laboral pierde vigencia y tienen vinculación con la edad y la estética corporal de las personas que la ejercen. En otras palabras, la calle tiene vencimiento y coloca tranqueras a las personas cuyo cuerpo se le ha transformado con los años y las deja invisibilizadas ante los prostituyentes y son rechazadas por los mismos, ya que demandan cuerpos jóvenes y esculturales. En consecuencia, las personas trans feminizadas deben buscar otras alternativas como Madelyn (2014):

(...) estoy mirando de que más adelante cuando tenga que dejar la calle no sé qué voy hacer... estoy buscando por otro lado, el tema es ahorrar y ver que puedo lograr con eso... Tengo algunos proyectos a ver si se me da, sé que un día la calle me va a cerrar las puertas también... por la edad, y porque los clientes buscan chicas jóvenes... 


\section{Abusos hay Constantemente, porque el Hecho de que Pagan y se Creen con el Derecho de... Todo...}

Los tatuajes que llevan grabados en el cuerpo a causa de la violencia, la discriminación y el estigma producen sentimientos que las hacen pensar que por la identidad que adoptan, no tienen ningún tipo de derecho. En la mayoría de los casos sienten que la felicidad, el bienestar y los vínculos de apoyo y de afecto familiar no les corresponden. Sentimientos que además generan conciencia sobre la inferioridad, anormalidad y marginalidad como propia de la identidad trans. Esto representa lo que Bourdieu llama violencia simbólica como forma particular de dominio, que:

impone una coerción que se instituye por medio del reconocimiento extorsionado que el dominado no puede dejar de prestar al dominante al no disponer, para pensarlo y pensarse, más que los instrumentos de conocimiento que tiene en común con él y no son otra cosa que la forma incorporada de la relación de dominio (BOURDIEU, 1998:22).

Además evidencia su fuerza incuestionable y la sutileza que la hace casi imperceptible ya que se presenta como natural y parte del mundo social. En los ambientes donde se ejerce la prostitución no están exentos de violencia sino al contrario, reside lo que Lagarde (2012) denomina las formas más relevantes del sexismo, es el machismo, la misoginia y la homofobia, cuya característica principal es el dominio masculino patriarcal. Este se basa en el androcentrismo, que crea valoración de lo masculino como superior a lo femenino y considera que los varones son socialmente los más capaces, los mejores; legitimando de esta manera el poder de dominio y la violencia. El androcentrismo se expresa en diversas características de los varones dentro de la estructura social: la condición masculina y la virilidad; en cuyo entorno existe una mezcla de agresión, fuerza dañina y dominación. En este sentido, resulta oportuno señalar voces de las protagonistas que dan cuenta del machismo en ese ambiente: 
Abusos los hay constantemente, porque el hecho de que pagan y se creen con el derecho de hacer absolutamente todo lo que se les ocurra, es abuso de poder. Y hay algo particular en las chicas que me ha pasado a mí también, es que yo me subía a un auto y estaba con el cliente, y por ejemplo me sacaba el corpiño para chuparme la teta y me desalineaba desde mi forma de vestirte, te sacan el maquillaje, quieren que los beses, cosas que vos no querés hacerlo, y ahi es donde está el abuso, es ahí donde ellos remarcan su pago, y más allá de que una no quiera, lo tiene que hacer porque en ese momento... inclusive se agarran de esa frase que dice "el cliente siempre tiene la razón”, yo soy el que pago vos tenés que hacer lo que yo te diga. Y muchas veces te pegan, y nosotras tenemos una particularidad, por ejemplo estamos en un grupo de chicas y a mi me levanta un auto, me voy con el cliente y me maltrata, me pega fisicamente, y yo como que hago una pared a ese maltrato, y cuando me bajo del auto lo único que me importa es la plata que me ha dado, yo ya no recuerdo que me ha hecho hacer cosas que no quería o que me pegaba independientemente de que me pagaba, eso no queda registrado en nuestra mente, dices vengo con $\$ 50$, tengo $\$ 100$, pero todo lo que me ha hecho no lo cuento (Luisa, Paz, 2014).

Yo creo que llegar a trabajar en la calle ha sido una de las peores experiencias de mi vida, que si pudiera retroceder el tiempo atrás no lo haría, no volvería a trabajar en la calle. He terminado en la calle porque a los 17 he comenzado a trabajar en un taller de costura..., todos abusaban porque me pagaban muy poco y trabajaba mucho. Ellos deciden cerrar el taller... y cuando cierran yo no sabía qué hacer, tenía 20 años. Consigo otro trabajo en otro taller, sigo trabajando ahí, a los 23 años dejo ese taller y no conseguía nada. Era complicado. En los talleres que he trabajado es porque era recomendada, entonces terminaba entrando asi a un laburo, porque si me presentaba así por un aviso en el diario me sacaban cagando, me decían bueno ya te vamos a llamar, y no me llamaban. Y bueno como pasaban los meses y no conseguía, he terminado por salir a la calle. He trabajado unos años, 2 o 3 no recuerdo bien en la calle, pero la experiencia en la calle en sí es horrible. Siempre es estar parada ahí y que te griten cosas, soportar a tipos que no quieres, la policía, el maltrato, la competencia que te genera el estar en la calle, competencia entre pares, eso también es algo que te molesta, asaltos. Mi experiencia en la calle horrible, no quisiera volver a la calle (Amelia, 2014).

Esto se entreteje y se completa con la misoginia, donde pareciera que lo masculino se posiciona con una sobrevaloración a tal punto que lo habilita acceder al cuerpo femenino para violentarlo incluso terminar con su vida. Las mujeres y las personas trans feminizadas son consideradas inferiores, subvaloradas e invisibilizadas, no se les reconoce características positivas. La misoginia, en tanto odio hacia lo femenino, está presente cuando se piensa y se 
actúa como si fuera natural marginar, maltratar, tener formas de comportamientos hostiles, agresivos y machistas hacia lo femenino y sus acciones. Para la autora, la misoginia es política ya que por el hecho de ser femenina es "discriminada, inferiorizada, denigrada y abusada, porque es marginada, sometida, confiscada, excluida o incluida a priori, y desde luego, porque por ser mujer, está expuesta al daño y ha sido previamente incapacitada para hacerle frente" (2012, p. 24). En este caso resulta significativa la vivencia de Madelyn:

- Por andar en la calle a deshora en la noche me han violado, y por confiar, por dejarme llevar.

- ¿Quieres contar lo de la violación?

- Sí, cuando tenía 16 años yo siempre me juntaba con un grupo de amigos y amigas, y una noche vengo como a las 2 de la mañana caminando y llegando a la banquina del canal ha salido alguien corriendo y me ha abrazado por detrás y yo no me podía soltar, pegaba patadas todo, y me ha metido a la casa de él, una casa esquina, y me decía que me dejara someter, que si o si iba a pasar, y lo ha hecho una, dos veces él. Una vez yendo a la escuela cuando estudiaba peluquería también me ha tocado en un camino en la oscuridad y no sé de dónde ha salido que no lo he visto ¿el mismo tipo? Si, el mismo, y yo no hablaba porque, yo crei que escondía mi homosexualidad, bah, mi sexualidad, ¿entendés? Y no hablaba, y ahi es donde me he equivocado, tendría que haber hablado. Y otra vez ha sido cuando he salido de un baile, y venía caminando y ellos, eran un grupo grande, que uno de ellos me decía que me iban a acercar, como eran amigos de mi amiga, de mi prima y de mi tía yo me he subido, y ha agarrado la ruta y yo decía que pare y todos se reían, se reían, eran como 8, y hemos llegado a ese lugar oscuro y ahi cuando ellos todos se bajan de la moto, yo soy la última en bajar y salir corriendo, y todos han quedado ahi y yo corría, corría y corría por la ruta y cuando me he dado vuelta no había nadie y corría y cuando he llegado al arco él me vuelve a pillar. Ese chico ha violado a muchas chicas, a mi amiga que está en Buenos Aires y la ha mandado al hospital...

Otra vez en Buenos Aires a los 25 años me ha levantado un cliente, y como yo no tenía hecho nada me costaba mucho trabajar. Era un gay travestido como se decía antes. Y yo ya quería operarme. Y en la desesperación me he ido a donde él trabaja, y cuando llego era un taller y estaba cerrada la persiana, le ha puesto candado. El tipo se ha desnudado y tenía cicatrices todo el cuerpo. Y él me decía que a mi me iba a pasar todo lo que a él le había pasado en la cárcel. Que a él lo había violado y le habían hecho esto, esto y esto y bueno. Me ha sometido sexualmente como activa y pasiva. Se ha abusado de mí. Y yo pensé que no iba a salir más de ahí. He sentido eso de que me iba a matar, por todo lo que yo veía en el cuerpo de él. Había muchas cicatrices grandes, como de peleas. Y bueno, no sé cómo pero al último me terminó pidiendo la plata que él me había dado, no me ha 
pegado, y me ha dicho que me vaya. Y esa noche estaba durmiendo yo con un chico, y esa noche me he sentido remil sucia, porque me ha hecho lo que ha querido, y he llegado llorando, le he confesado a mi pareja, y él me abrazaba y me he metido en el baño y no he salido más. Sentía el dolor de él. En un momento tenía mucho miedo en tomar esa decisión. Y ahí se me ha cruzado la imagen de mi madre, de reventarlo con un hierro cuando él estaba agachado delante de mí. Le he pedido que me ayude y bueno, ahi estoy. Siete veces me han violado en mi vida...

No, habíamos arreglado por $\$ 50$ la penetración y él me ha dicho bueno vamos, y ahi me sale con $\$ 10$ pesos y él me ha querido violar...me ha querido violar, me ha querido tener a la fuerza hemos estado en el piso revolcándonos y he safado...

Como podemos observar a través de los relatos también estuvieron y están vulnerables a ser violadas por resistir o negarse a situaciones propuestas por el prostituyente o por el solo hecho de ser trans y tener un cuerpo deseoso para los varones, son algunas de las posibles justificaciones. En consecuencia y debido a la marginación, estigmatización social y al momento histórico en el que vivieron, por lo general, no recurrían a la justicia para denunciar, pues desde allí recibían burlas o se las culpabilizaba por lo acontecido. Asimismo, lejos de tener protección policial, en muchos lugares eran detenidas bajo cualquier "excusa, o por motivos que se inventan en el momento para tratarlas como delincuentes porque están siendo victimizadas" (MACKINNON, 2011, p. 21). En otros casos, argumentaban desde las representaciones sociales, la mala reputación que representan, la pertenencia al mundo de la prostitución y de la droga como exclusivo del colectivo trans. En la actualidad esas situaciones se han modificado, no solo que las personas trans feminizadas hoy ejercen la prostitución sin ser arrestadas por su actividad sino que, en algunos casos, tienen como prostituyentes a varones que pertenecen a la fuerza que antes la arrestaba.

La homofobia, es otra forma en la que se expresa el machismo, concentra actitudes y acciones hostiles hacia las personas trans feminizadas y hacia aquellas que se sienten atraídas por alguien del mismo sexo. La masculinidad dominante es intolerante para con la homosexualidad. Y como en las otras formas de sexismo, la violencia contra ellas se considera legítima, incuestionable y justificada. Tiene sus raíces en la discriminación histórica y la ausencia de derechos que han sufrido y continúan padeciendo (VARELA, 2005). "Se expresa a través de conductas y actitudes basadas en un sistema de creencias sexistas y heterocentristas, que tienden a acentuar las diferencias apoyadas en los estereotipos de género, conservando las estructuras de dominio" (CHAHER y SANTORO, 2007, p. 163).

En contextos de violencia como el que venimos señalando, y para continuar pensando el dominio que ejercen los varones prostituyentes sobre las personas trans feminizadas prostituidas es significativa la explicación que brinda Segato:

Sobre este sujeto pesa el imperativo de tener que conducirse y 


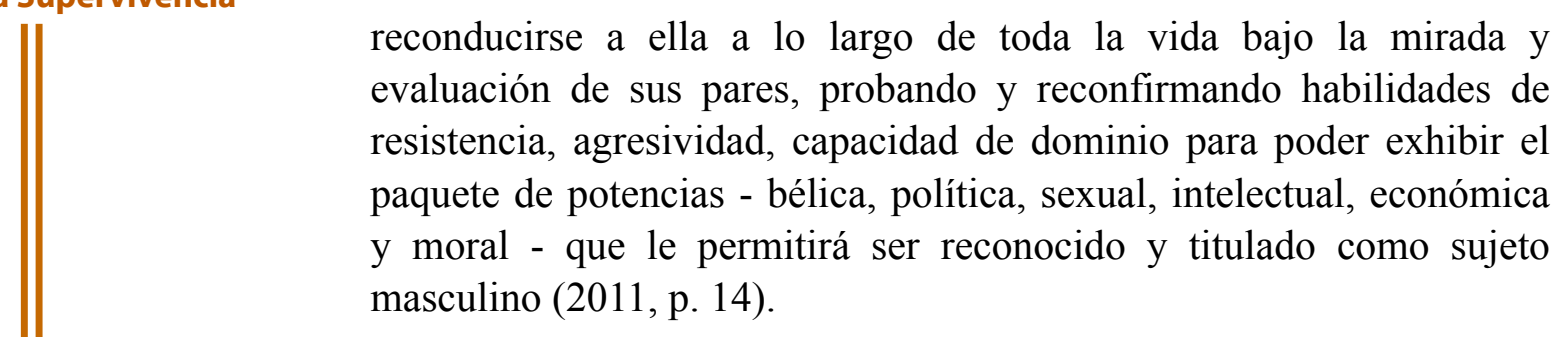

La violencia contra las personas trans feminizadas en situación de prostitución hace que se sientan menospreciadas ante sí mismas y las demás. De igual manera, atenta contra su identidad ya que refuerza y reproduce la subordinación de lo femenino. La violencia contra ellas pone en riesgo el derecho a la vida, a la libertad y a la seguridad personal. En algunos casos son asesinadas por el tipo de ocupación que realizan (el ejercicio de la prostitución), que además acrecienta la vulnerabilidad al realizar una tarea destituida o estigmatizada, aunque para el consumo no es vista de la misma forma. En este sentido, un dato relevante del informe del CIDH señala que la mayoría de las mujeres trans asesinadas son menores de 35 años de edad.

En este marco de situación, los varones cuando pagan por sexo se prostituyen, ya que prostituir es un verbo que se conjuga habitualmente con un sujeto trastocado (CHEJTER, 2011). Sin embargo, en el entorno social el término se utiliza para referirse a las mujeres y a las personas trans feminizadas que ejercen la prostitución, no así para los que pagan. En consecuencia, los prostituyentes son seres anónimos, comunes e invisibles. Se los muestra como seres inocentes, víctimas ante el estímulo y la facilitación en tanta oferta; lo que refuerza el estereotipo de la sexualidad como expresión de la naturaleza de los varones (VOLNOVICH, 2010). Tal es así, que los prostituyentes pretende vivir su vida, satisfacer sus necesidades y sus fantasmas, como una curiosidad o como una relación sin compromiso (CHEJTER, 2011).

Cabe señalar, que los varones que pagan por sexo también son diversos en las prácticas sexuales que mantienen con la persona trans feminizadas donde cumplen el rol de activo, pasivo o ambos. No obstante, en ellos existe la ambivalencia del típico macho prostituyente que jamás se reconocería a sí mismo como homosexual, aunque se sienta atraído por una mujer trans. Entonces es el deseo que se despierta pero también el odio por haber caído en la trampa de una relación homosexual.

Para evitar algunas situaciones de violencia padecida en la calle cuando ejercen la prostitución, aprenden y emplean estrategias, como Olga que usa botas sin tacos para correr:

- En mi caso personal yo tacos no uso, porque me traen problemas, no. Yo salgo de botas, porque ahí escondo todo, llavero, llaves, celular, todo. Nunca salgo desnuda, salgo de calzas y tops.

- ¿Y en la cartera?

- Gel, preservativo, papel higiénico, maquillaje, todo eso.

- ¿Por seguridad?

-Claro, por seguridad, yo me siento mejor teniendo las cosas en las botas porque puedo correr, todo; en cambio con tacos no y no te 


\begin{abstract}
conviene estar parada muchas horas. Cada una elige, muchas chicas usan tacos y no hay problema.

Otra estrategia que utilizan es estar parada en una esquina con otras compañeras, para sentirse acompañada y protegida entre pares. Esa protección pierde vigencia cuando se retiran del lugar con el prostituyente para concretar los servicios.

\section{Caías Presa, te Rapaban y te Sacaban la Ropa de Mujer,... nos Largaban Desnudas}

En nuestro país la prostitución no está prohibida ni configura un delito si es ejercida por propia voluntad. Sin embargo, el art. 126 de Código Penal establece que será reprimido con reclusión o prisión de cuatro a diez años, el que con ánimo de lucro o para satisfacer deseos ajenos promoviere o facilitare la prostitución de mayores de dieciocho años de edad mediante engaño, abuso de una relación de dependencia de poder, violencia, amenaza o cualquier otro medio de intimidación o coerción (BRUNO, 2008, p. 5).
\end{abstract}

En la Década del 90 hasta no hace muchos años era muy frecuente que las personas que ejercían la prostitución sean víctimas de detenciones y maltratos por parte de la fuerza de seguridad. Desde allí, aparecen distintas figuras como prostitución escandalosa, molesta, peligrosa, exhibición obscena, que permiten a la fuerza de seguridad intimar y amenazar a quienes la ejercen. "Si bien se trata de conflictos que no figura un delito penal, esto no impide que el Estado ejerza un poder punitivo sobre las trabajadoras sexuales: detención y multas son las sanciones más frecuentes" (BRUNO, 2008, p. 5). Esto recibe el nombre de violencia institucional que hace referencia a "prácticas estructuradas de violación de derechos por parte de funcionarios pertenecientes a fuerzas de seguridad, fuerzas armadas, servicios penitenciarios y efectores de salud en contextos de restricción de autonomía y/o libertad (detención, encierro, custodia, guarda, internación, etc.)" (ARMIDA y otros, 2015, p. 7).

Actualmente, las integrantes de AMMAR sostienen que hechos de esta naturaleza siguen ocurriendo en 18 provincias del país donde tienen vigencia los códigos contravencionales de convivencia que sancionan conductas ciudadanas desde una mirada de la moral pública; de las que Santiago Del Estero no forma parte. "Tales medidas comprenden multas y arrestos de hasta 60 días para las personas que ofrecen servicios sexuales en la calle y habitan el ejercicio sistemático de violencia institucional por parte de la fuerza de seguridad" (AMMAR, 2016:9) En este contexto, autoras como Orellano, Varela y Daich (2014) sostienen que esta violencia contra las trabajadoras sexuales se ha intensificado con las políticas antitrata a partir de la sanción de la ley de trata en el año 2008 y luego la modificación en el 2012 convirtiéndose en ley 26842. Consideran que están expuestas a allanamientos, y otros proceso de investigación destinados a la búsqueda de casos de trata y son siempre sospechadas de ser víctimas.

Parte de la sociedad parece indiferente y en muchos casos contribuye a que 
estas prácticas se sigan perpetuando, a través de, denuncias hacia quienes ejercen la prostitución colocándose bajo el paraguas de la moral pública, o lo hacen a través del silencio frente a los abusos por parte de la fuerza. Por parte de la sociedad, no se ha visto hechos de repudio contra la institución. En efecto, podemos pensar que no se trata de una policía intolerable a la prostitución sino de un organismo que cumple en estos casos con las tareas que le pide la sociedad, que algunas puede ocurrir legal e ilegalmente, como los siguientes casos:

El principal problema era la policía, que nos arrestaba, 12, 16, 18, 24 horas. Pero problemas con los clientes nunca tuve, muy pocos, ni me acuerdo, porque más o menos elegía. No quería arriesgarme. Siempre he pensado: primero yo y después la plata (Olga, 2014).

...Cuando tenía 11 me mandan a Buenos Aires a la casa de mis abuelos, en el año, 77, 78. Y yo desaparezco de Santiago del Estero. En la esquina de la casa de mis abuelos vivía una chica trans, y yo no entraba a la escuela, me quedaba en la casa de ella y por entremedio de ellas me llevan a la calle a trabajar. La primera noche no caigo presa, ya a la segunda noche si caigo presa... Lo más horrible es que en la provincia vos caías presa te rapaban y te sacaban la ropa de mujer, varias veces sali desnuda de la comisaría, porque nos largaban desnudas. Es dura la calle, dura. Un horror, en pleno invierno nos desnudaban y nos tiraban en el calabozo. De aquí creo que soy la que más he sufrido esa época allá en Buenos Aires (Mari, 2014).

Este calvario es más tormentoso cuando en la familia desconocen la actividad que realizan porque se descubren a partir de los hechos. La incomprensión y la falta de apoyo familiar dificultan sobrellevar tanta violencia:

(...) y cuando me junto con Jacqui ya me meto en la prostitución, es asi donde me detienen, yo era menor, y ahi es donde ha sido el momento de enfrentar la realidad. Ha llegado la situación a mi casa que vayan a buscar al menor porque se estaba prostituyendo. Y mi mami no me ha ido a buscar, ha ido mi hermano, y cuando yo llego ella estaba parada en la puerta y yo ya decía bueno me va a golpear, era terrible, yo le tenía terror. Y nada, pasar esa puerta para mí era pasar al final, no que me iba a matar, sino que pasar esa puerta era quedarme en la calle. Y me he equivocado, ahi es donde ella me ha hurgado mi ropero, mi roperito azul que todavía existe, a buscar mi documento, y ahi a encontrado ropa de mujer, la peluca, algunas cosas que yo me he comprado, una camisa de mi hermana que ella me prestaba. Y me ha preguntado qué era eso y ya no habia forma de negar, y ahi me he puesto a llorar y le he dicho que yo me sentía así, lloraba y no se me entendía al hablar. Al fin y al cabo lo que me ha dicho que ella quería que haga respetar la casa y que me cuide. No sé, ese día me voy a la escuela y cuando vuelvo siempre nos 
juntábamos así a las 11 de la noche con Jacqui, y esa misma noche me he pintado en mi casa y esa noche he salido de taquitos. Ese día mi mami quería que me corte el pelo todo, yo tenía el carré, y le había dicho que yo tenía que ayudar en la escuela y tenía que ir para que las chicas practiquen, que yo tenía el pelo largo hecho la permanente, y ahi quería que me corte el pelo. Y cuando yo me he soltado ha desistido, ha comenzado a desaparecer mi ropa de varón, y ya todo era diferente (Madelyn, 2014).

La lucha de las organizaciones ha posibilitado la derogación de los códigos que las criminalizaban. Lo que significa que las personas que ejercen la prostitución hoy no sean perseguidas ni detenidas. En Santiago del Estero, ATTTA y AMMAR (Asociación de Mujeres Meretrices de Argentina), hicieron posible en el año 2008, la derogación del código, luego de un arduo debate en la cámara de diputados. Rosa (2013) hace alusión al respecto:

Te pedian plata, o trabajabas para la policía... eso ha sido mientras existía el código... luego, la policía no ha cambiado, lo que ha cambiado, ha sido que nosotras a través de gestiones lo que hemos hecho es quitarles las herramientas que tenían para levantarnos cuando trabajábamos en la calle que era un código contravencional, que te podían levantar por el solo hecho de estar vestida de ropa femenina. Entonces, al no tener esa herramienta ellos, han tenido que actuar de otra manera porque ya no tenían las herramientas no es que les ha cambiado la cabeza, y que ahora nos acepten y nos quieran, no. Deben pensar lo mismo, deben seguir siendo igual de hijos de mil puta que antes, pero ya no tienen las herramientas y esa herramienta se las hemos quitado las organizaciones civiles trabajando, pidiendo en la cámara de diputados, andando...hemos logrado que en la cámara de diputados se trate el tema y lo han levantado al código contravencional que estaba desde el tiempo de los militares. Entonces ya no tiene la policía manera de tocarte, no tiene las herramientas entonces no les queda otra que aceptarte pero no creo que la cabeza les haya cambiado a ninguno a uno de esos infelices, porque cada vez que hemos necesitado hemos tenido que sentir por lo menos el maltrato, ¿entiendes?, por lo menos el maltrato, quizás ahora una gestión te la hacen.

En las trayectorias de personas trans es destacable la resistencia que vienen haciendo frente a tanta violencia y discriminación.

En confrontación con el orden socio-sexual las travestis/transexuales han conseguido organizarse y responder contra los múltiples abusos provenientes de las agencias del Estado. En el camino han aprendido a reconocer sus derechos y defenderlos y se han aliado a otros grupos y organismos entendiendo que si efectivamente el pacto social de la modernidad es un pacto de exclusión, entonces, la única respuesta a él es la alianza de las/os excluidos (BERKINS y FERNÁNDEZ, 2013, p. 64). 


\section{Dame un Regalito y Vas a Estar Protegida}

Las personas que forman parte del presente estudio, ejercen o ejercieron la prostitución en un contexto de marginación, discriminación y exclusión. En algunos casos, además se les exige el pago del lugar que ocupan en la calle para ofrecer los servicios, que en la jerga de las personas prostituidas recibe el nombre de "plaza". Quienes se niegan a pagar no pueden pertenecer a ese sector ya que es considerada propiedad de la que mayor antigüedad tiene en ese espacio. Quienes pagan lo hacen porque son aprendices o porque consideran el pago como natural. Otras hacen frente al problema teniendo carácter, intentan resistir y defender lo que consideran como derecho. Las personas que cobran y se benefician a través de la prostitución ajena, reciben el nombre de fiolo, cafisho, proxeneta u otros si pertenecen al género masculino y madama al femenino. Muchas veces utilizan la violencia, la amenaza para conseguir el objetivo. Algunas protagonistas hacen referencia al respecto:

- En Mar del Plata regentean, la zona donde nosotras trabajábamos tenés que pagar 1000 pesos para entrar. Regenteaba todo la misma trans, $y$ vos te parabas en una esquina, y pagabas 50 pesos por semana por la esquina.

- ¿Para quién?

- Para ella, que era la dueña de la zona, arreglaba con la policía, todo eso (Olga, 2013).

Aqui en Santiago, hay una chica trans muy conocida en el ambiente que exige el pago, llega al lugar y nos dice. Dame un regalito y estarás protegida. A quien le hagas la entrevista pregúntales, todas la conocen, es agresiva, le tenemos miedo, no ejerce la prostitución, vive de la recaudación que hace de las compañeras, hasta tiene auto (Ruth, 2016)

- Aqui en Santiago y en Buenos Aires, han querido hacerlo conmigo a lo cual yo por negarme me han pegado, me han dado una cachetada. No me he podido defender porque detrás habia diez.

- ¿Y qué te han querido hacer?

- Obligarme a que yo les pague plaza. Y no, no lo he hecho, me he quedado y he insistido. Porque lo tengo que hacer si, primero tengo derecho, la calle no es de nadie, yo me estoy sacrificando no ella... Plaza se le llama a donde se está parada. ¿Entiendes? No soy ni siquiera ilegal. Este es mi país. Y nadie puede venir a decirme, de venir a cobrarme porque yo este parada... (Madelyn, 2013).

Tal como lo señala Madelyn, no es ilegal ejercer la prostitución en la Argentina porque no está prohibida ni configura un delito. Sin embargo, la función que desempeña un fiolo o una madama es considerado/a un delito, mediante la Ley Nacional $N^{\circ} 26364$ de prevención y sanción de la trata de personas y asistencia a sus víctimas promulgada en el 2008 y luego modificada en el 2012 con la $\mathrm{N}^{\circ}$ 26.842. En esta última "Se entiende por trata de personas el ofrecimiento, la captación, el traslado, la recepción o acogida de personas con fines de explotación". Allí contempla "cuando se promoviere, facilitare o 
comercialice la prostitución ajena o cualquier otra forma de oferta de servicios sexuales ajenos". No obstante, estos hechos como otros no son denunciados, por lo general las personas de mayor antigüedad en la zona regentean a las más nuevas, quienes son de poca experiencia en la calle.

\section{Las Organizaciones Son el Salvavidas, es la Única Oportunidad de Desarrollarte como Persona Plena, con Todos tus Derechos}

La puta y la prostitución son terrenos políticos donde podemos aprender, encontrar y ubicar mecanismos de dominación que son claves para deshacer, desde lo más profundo, las cadenas de opresión de las mujeres y, a partir de nosotras, del conjunto de las relaciones de dominación en nuestras sociedades (GALINDO y SÁNCHEZ, 2007, p. 34).

La organización de personas trans es importante para el colectivo, pues constituyen un antes y un después luego de conocerla, interiorizarse y compartir temas en común, con diferencias y similitudes. Por lo general, llegan cargadas de miedo, soledad, angustia y cansancio por las vivencias transcurridas y allí logran aliviar la mochila del sufrimiento al conocer que no están solas como pensaban.

Las asociaciones son valoradas como lugares en los que se reconocen los derechos y en los que pueden derribarse ideas erróneas respecto de su identidad travesti, aquellas en las que, según Bourdieu, y lo ilustra el siguiente testimonio, el punto de vista de la clase dominada es el punto de vista de la clase dominante (FERNÁNDEZ, 2004, p. 118).

En ese tiempo, a los 23 años, me han hecho conocer a Luisa, que ella tenía una organización, y me han traído a la casa de Luisa. Cuando yo he llegado la Luisa me ha comenzado a hablar, hablar, hablar y lo primero que me hace hacer es el análisis de VIH, y ahi ella me ha comenzado a meter en esto del activismo. Y de ahi he comenzado a pensar otras cosas, y ahi he dejado la calle, porque el estar en la organización a mí me ha servido para darme cuenta que podía hacer otras cosas. He seguido buscando laburo, laburando en talleres, siempre en costura porque como no he terminado mis estudios... Y el año pasado he decidido, después de las leyes y todo, he decidido estudiar, terminar la secundaria que es algo que tengo pendiente. Con mucho miedo obviamente por todo lo que ha pasado, el rechazo, y tenía como mucho miedo de volver a la escuela y enfrentarme con toda una institución y ver cómo me iban a tratar, pero más segura porque sabía que ahora tenía derecho, pero me taparon la boca en el colegio porque totalmente diferente a lo que yo pensaba que iba a ser, porque es también un colegio religioso. Pero bien el trato sobre todo de los profesores, de los compañeros ni hablar. El Gottau es un colegio privado para adultos semipresencial. Estoy ahi. Terminando 


\begin{abstract}
la secundaria y a ver si sigo en algo... (Amelia, 2014).
Las organizaciones constituyen una oportunidad, permite a las personas trans feminizadas hablar sobre sus trayectorias donde la violencia y el delito forman parte de su propia imagen.

A través de ellas se relacionan con otros grupos y personas cuya solidaridad y compromiso se presentan como las "nuevas armas" con la que hacen frente a sus vidas y esto contribuye, a su vez a la erradicación de aquellas imágenes que la vinculan al crimen. Desplazado como atributo identitario gracias al activismo, el crimen es, ahora, puesto fuera de ellas (FERNÁNDEZ, 2004, p. 119).
\end{abstract}

En este sentido, el relato de Luisa Paz (2015) es representativo:

Ahi yo no estoy de acuerdo, la sociedad no tiene que cambiar, sino nosotras tenemos que hacer que cambie. La sociedad no se va a levantar un día y va a decir ah bueno ahora amamos a todas las trans $y$ todas las trans tienen que ser madres. No, hay que romper los paradigmas, hay que imponerse a eso, y la gente te va a ver de otra manera. Y no estar esperando que el otro cambie... los otros están en una posición cómoda. No son ellos los que padecen discriminación, los que sufren o que tienen necesidades en ese sentido. A lo mejor los tienen desde otro lugar. Pero somos nosotras las que necesitamos que nos reconozcan o poder hacer estas acciones sin temor a que nos critiquen o nos cuestionen porque somos trans o nos tilden de violador o pedófila o tantas cosas que se dicen. Nosotras tenemos que hacer nuestro aporte, los otros están en una posición cómoda, los otros no van a cambiar porque están cómodos, no van a cambiar si no hacemos algo nosotras, ¿por qué van a luchar por lo que no les duele?, si a ellos no les duele nada.

Las personas trans feminizadas mediante la organización realizan trabajos de prevención y educación entre pares. Algunas tareas que realizan son las campañas en las calles con el objetivo de llegar a las compañeras más ocultas, en situaciones de mayor discriminación o que viven en soledad. La educación que promueven y al mismo tiempo que reciben es sobre prevención, detección temprana y tratamiento del VIH/SIDA, Derechos Humanos, Identidad, acceso a la salud y educación, asesoramiento sobre las inyecciones de siliconas, causas y consecuencias. En el año 2016 se reunieron semanalmente durante dos meses aproximadamente en ATTTA (sede Santiago) formando un espacio de contención mutua donde compartieron vivencias que les afectan en la vida, fue una especie de terapia grupal. Además al finalizar cada encuentro se elegía entre las presentes una candidata para la presidencia de la organización, que en el último encuentro finalizó con la elección de una de ellas.

'A su vez las acciones de prevención y la autoorganización potencian el trabajo en red tanto a nivel provincial como nacional e internacional, dando la posibilidad de que se integren otras compañeras. 
El trabajo entre pares constituye una estrategia cuyas acciones son desarrolladas por personas que se encuentran en la misma situación que aquellas a quienes están dirigidas esas acciones. Esto significa un mayor grado de comprensión, entendimiento y efectividad en las tareas a desarrollar. Esta estrategia promueve la participación de las trabajadoras sexuales en el cuidado de su salud y en la prevención de enfermedades (BRUNO, 2008, p. 23).

Además, luchan contra la estigmatización, realizan tareas de visibilización social y promoción de sus derechos que ocupan gran parte de sus energías. Asimismo, ejecutan estrategias de denuncias e inciden políticamente frente a los organismos del Estado como la llegada a funcionarios/as, jueces/juezas y legisladores/as quienes tienen posibilidad de tomar decisiones en las políticas públicas. Trabajan en conjunto con otras organizaciones que comparten temáticas de común interés.

El trabajo con las organizaciones...es la única oportunidad de tener una vida digna para una chica trans, es el salvavidas, es el único camino posible para que puedas desarrollarte como una persona plena, con todos tus derechos porque aqui encuentras a gente que está en la misma que vos y que estás conectada con ciertas áreas del Estado, que pueden asegurarte derechos como el trabajo, la salud y la educación. Las organizaciones civiles casi siempre tenemos que meter mucha presión o sea nada se nos es fácil ¿no es cierto?, es como que tienes que ir abriendo puertas, no te las abren a las puertas, las abres vos... (Rosa, 2014).

La mayoría de las personas trans feminizadas viven en situación de pobreza, lidian permanentemente con el estigma, la discriminación y la exclusión, elementos que profundizan la exclusión a los servicios sociales básicos y su posibilidad de exigirlo. En consecuencia, las organizaciones, median entre las personas que la integran y los organismos estatales para demandar necesidades (individuales o colectivas) y así conseguir recursos o la ejecución plena de algún derecho. Actúan como representantes de las personas que no pueden demandar por diferentes motivos. De esta manera la organización ATTTA y DIVAS en Santiago del Estero ha logrado conseguir un espacio físico, microemprendimientos, en algunos casos trabajo, planes, tarjetas sociales, entre otros beneficios. Si bien a través de estas acciones no logran salir de la pobreza ni tampoco las exime de la discriminación pero contribuye a la inserción laboral y social, además toman conciencia sobre sus derechos y pueden mejorar sus capacidades de negociación para optimizar las condiciones de trabajo.

Aún con las diferencias que existen entre ellas y que las caracterizan, las organizaciones de personas trans tienen un proyecto común por el cual luchan: comparten preocupaciones, exploran nuevos escenarios, se proyectan políticamente. Valoran el espacio como un espacio de escucha, de lucha y de confrontación contra los patrones culturales y buscan incidir en los espacios 


\begin{abstract}
que históricamente han sido excluidas. Dan a conocer su situación de vida y el riesgo al que están expuestas. Como consecuencia de todas las acciones que vienen realizando han ganado espacio en los medios de comunicación ${ }^{3}$, y lo utilizan para difundir información de su interés o para denunciar algún hecho.

Para concluir, las organizaciones de personas trans en su accionar, invitan a sus compañeras a desobedecer y romper con las normas sociales impuestas, a vencer el miedo, y a manifestar lo que piensan, sienten y lo que son. Asimismo, estimulan a la sociedad en general a desestructurar las mentes y los cuerpos que han señalado lo normal y lo anormal para darse la oportunidad de conocer y aceptar que hay otras formas de ser además de varones y mujeres, que no existen solo dos géneros sino que hay multiplicidades de géneros, sexualidades y cuerpos que merecen ser respetados. Y que a su vez, la diversidad no sea un condicionante para pertenecer a determinada familia, ni para recibir educación, salud, vivienda, o accesos a otros derechos.
\end{abstract}

\title{
A Modo de Cierre
}

Las personas trans feminizadas ejercen múltiples resistencias con sus identidades, sus cuerpos y sus sexualidades. Resisten tanto al sistema de categorías identitarias como al modelo de género a partir del sexo que se impone (femenino y masculino) y resisten al sistema patriarcal y a la heterosexualidad como parte de éste. Son cuerpos rebeldes que buscan libertades y en contraposición son débiles ante los ataques sociales, el momento de tránsito es la etapa que mayor condena social recibe. Los primeros comienzos son duros, la transexualidad no es algo que pueda disimular y pasar desapercibida como otras identidades.

Generalmente, ingresan a la prostitución en la adolescencia, lugar del que quieren alejarse y conseguir otra actividad de la que puedan subsistir. En ese sentido, demandan al Estado trabajo y vivienda para salir del ambiente, que tanto las violenta, no solo físicamente por parte de los prostituyentes o de otros varones, sino también verbal, psicológica, y económica. Además, la expone a violaciones, a violencias por parte de la policía, a trata de personas con fines de explotación sexual y a riesgo de muerte. El trato que tienen con los prostituyentes es desigual y jerárquico. Son limitadas las posibilidades de negociación, al mantener una relación jerárquica que indica al prostituyente con decisión para la compra de servicios que desea y a las personas trans feminizadas con necesidad de obtener dinero para subsistir, arriesgándose a situaciones que no desean, para lograr lo que necesitan.

En la calle, las personas trans feminizadas presentan su identidad como desean, reparan su autoestima y sus deseos, pudiendo desplegarse con mayor libertad. Al mismo tiempo, el entorno está condicionado por patrones culturales que moldean las conductas y comportamientos de las personas que ingresan al ámbito de la prostitución. Allí la construcción del género femenino es a partir del estereotipo de mujer definida socialmente. Para lograr ese cuerpo femenino se somete a diversas intervenciones que ponen en riesgo la salud y la vida de ellas y de sus compañeras, proceso en el que también se

3 Luisa Paz tiene una columna semanal en la radio de la U.N.S.E que se llama "diversidad sexual". 
encuentran solas y sin la supervisión médica correspondiente.

La organización de personas trans feminizadas es de suma importancia para el colectivo ya que se reconocen los derechos, pueden adquirir conocimientos y desaprender ideas erróneas sobre su identidad. Les brinda la oportunidad de conocer otras compañeras y trabajar en coordinación. Aún con las diferencias entre ellas que las caracterizan, las organizaciones de personas trans feminizadas tienen un proyecto común por el cual luchan: comparten preocupaciones, exploran nuevos escenarios, se proyectan políticamente. Valoran el espacio como un espacio de escucha, de lucha y de confrontación contra los patrones culturales y buscan incidir en los espacios que históricamente han sido excluidas. Ejecutan estrategias de denuncias e inciden políticamente frente a los organismos del Estado como la llegada a funcionarios/as, jueces/juezas y legisladores/as quienes tienen posibilidad de tomar decisiones en las políticas públicas. Trabajan en conjunto con otras organizaciones que comparten temáticas de común interés.

\section{Bibliografía}

AMMAR. Trabajadoras sexuales argentinas en acción por sus derechos. Buenos Aires: Asociación de mujeres meretrices de la Argentina, 2016.

ARMIDA, Maria Gimena y otros. Los Derechos Humanos frente a la Violencia Institucional. Buenos Aires: Ministerio de Justicia y Derechos Humanos, 2015.

BERKINS, Lohana; FERNÁNDEZ, Josefina (Coords). La gesta del nombre propio. Informe sobre la situación de la comunidad travesti en la Argentina. Buenos Aires: Madres de Plaza de Mayo, 2013.

BERKINS, Lohana; KOROL, Claudia. Diálogo prostitución/trabajo sexual: las protagonistas hablan. Buenos Aires: Feminaria, 2007.

BOURDIEU, Pierre. La dominación masculina. En: BOURDIEU, Pierre; HERNÁNDEZ, Alfonso; Rafael. La masculinidad. Aspectos sociales y culturales. Quito: ABYA-YALA, 1998, p. 9-107.

BOURGOIS, Philippe. En busca de respeto. Vendiendo crack en Harlem. Buenos Aires: Siglo XXI, 2010 (1995).

BRUNO, Daniela. De la desigualdad a la diferencia: sistematización de experiencias de prevención del VIH/SIDA con población transexual. Buenos Aires: Ubatec S.A, 2008.

CABRAL, Vinicius; SILVA, Joseli Maria; ORNAT, Marcio. Espaços de Morte e Representações Sociais deTravestis na Cidade de Ponta Grossa- Paraná. Revista Latino-americana de Geografia e Gênero, v. 4, n. 1, p. 139 - 161, 2013. 
Las Personas Trans Feminizadas y la Prostitución como Último Recurso para

la Supervivencia

CHAHER, Sandra; SANTORO, Sonia (Comps). Las palabras tienen sexo: Introducción a un periodismo con perspectiva de género. Buenos Aires: Artemisa comunicación Ediciones, 2007.

CHAZARRETA, Irma Elizabeth. Prostitución y Salud: experiencias invisibilizadas de mujeres y personas trans en Argentina. Rev. Reflexiones de la Facultad de Ciencias Sociales de la Universidad de Costa Rica, v. 95, n. 1, p. $157-167,2016$.

CHEJTER, Silvia. Lugar común: la prostitución. Buenos Aires: EUDEBA, 2011.

FERNÁNDEZ, Josefina. Cuerpos desobedientes: travestismo e identidad de género. Buenos Aires: Edhasa, 2004.

FERNÁNDEZ, Josefina. El género en llamas. Travestismo e identidad genéricas. Feminarias, v. 26, n. 30/31, p. 25 -35, 2007.

DAICH, Deborah. ¿Abolicionismo o reglamentarismo? Aportes de la antropología feminista para el debate local sobre la prostitución. Runa Archivos para la Ciencia del Hombre, v. 33, n. 1, p. 71 - 84, 2012.

GALINDO, María; SÁNCHEZ, Sonia. Ninguna mujer nace para puta. Buenos Aires: La vaca, 2007.

GUBER, Rosana. La Etnografía. Método, campo y reflexividad. Buenos Aires: Ed. Norma, 2004.

LAMAS, Marta. Usos, dificultados y posibilidades de la categoría género. La ventana - Revista de estudios de género, n. 1, p. 10 - 61, 1995.

LAGARDE y DE LOS RÍOS, Marcela. Los cautiverios de las mujeres: madresposas, monjas, putas, presas y locas. México DF: Universidad Nacional Autónoma de México, 2011.

LAGARDE y DE LOS RÍOS, Marcela. Feminismo en mi vida: hitos, claves y topías. México: Instituto de las Mujeres del Distrito Federal, 2012.

LEY NACIONAL N $\mathrm{N}^{\circ}$ 26.364. Prevención y sanción de la trata de personas y asistencia a sus víctimas, 2008.

LEY NACIONAL N ${ }^{\circ} 26.842$. Trata de personas y asistencia a sus víctimas: prevención y Sanción, 2012.

MACKINNON, Catherine. Trata, prostitución y desigualdad. En: Discriminación y género. Las formas de la violencia. Buenos Aires: Defensoría General de la Nación, 2011. 
Las Personas Trans Feminizadas y la Prostitución como Último Recurso para

la Supervivencia

ORELLANO Georgina; VARELA, Cecilia; DAICH, Deborah. Políticas antitrata $y$ vulneración de derechos de las trabajadoras sexuales. RedTraSex Latinoamérica y el Caribe, 2014.

QUIRÓS, Julieta. Neoaluvión zoológico. Avatares políticos de una migración de clase. Cuadernos de Antropología Social, n. 39, p. 9 - 38, 2014.

RUBIO, Ana. La teoría abolicionista de la prostitución desde una perspectiva feminista. En: FERNÁNDEZ, Holgado I. (ed.) Prostituciones. Diálogos sobre sexo pago. Barcelona: Icaria, 2008.

SEGATO, Rita. Género y colonialidad: en busca de claves de lectura y de un vocabulario estratégico descolonial. En: BIDASECA, Karina; LABA, Vanesa Vázquez (Comp.). Feminisimos y Poscolonialidad. Descolonizando el feminismo desde y en América latina. Buenos Aires: Ed. Godot, 2011.

SILVA, Joseli María. A Cidades dos Corpos Transgressores da Heteronormatividades. In: Silva Joseli María (Org). Geografias subversivas: discursos sobre espaço, gênero e sexualidade. Ponta Grossa: Toda Palavra, 2009 , p. $136-149$.

VARELA, Nuria. Feminismo para principiantes. Barcelona: Ediciones B, S.A., 2005.

VOLNOVICH, Juan Carlos. Ir de putas. Reflexiones acerca de los clientes de la prostitución. Buenos Aires: Topia, 2010. 